\title{
Short-Term Outcomes of Very Low Birth Weight Infants at a Tertiary Care Center in UAE Compared to the World
}

\author{
Nusrat Khan, Aiman Rahmani, Mustafa Al Abdullatif, Abu Sa'da and Rasha Masoud* \\ Tawam Hospital in Association with Johns Hopkins International, Department of Pediatrics, UAE
}

*Corresponding author: Rasha Masoud, Neonatology Consultant, Department

of Pediatrics, Tawam Hospital, Al Ain, United Arab Emirates.

Received Date: September 16, 2019

Published Date: September 18, 2019

\section{Abstract}

Background: Very low birth weight infants make up a small percentage of total live births but contribute significantly to neonatal intensive care unit admissions and mortalities. Their survival rate has increased greatly in developed countries due to advanced perinatal health care but developing countries still lag.

Aims: Examine the mortality and morbidity rates in VLBWI in a tertiary neonatal care center in UAE and compare these to previously published data from the same center (VLBWI outcomes during 2004-2006, labeled period I), the region and international neonatal networks.

Methods: Demographic and multiple outcome data were collected from annual audits of the unit on a VLBWI cohort (500-1500g) admitted between January 2011 and December 2015.

Results: Of the 468 infants weighing 500-1500g at birth, $82 \%$ survived until discharge (85.6\% in period I), 33\% had Chronic Lung Disease (12.1\% in period I), $10 \%$ suffered from necrotizing enterocolitis (5.8\% in period I), $22.2 \%$ had Intraventricular Hemorrhage of any grade $(17.5 \%$ in period I) while $3.8 \%$ had Periventricular Leukomalacia ( $2.8 \%$ in period I). Cesarean sections were conducted $75 \%$ of the time (55.5\% in period 1) and $49 \%$ cases were multiple births (33.9\% in period I). These outcomes were also compared to regional reports and international neonatal networks.

Conclusion: Mortality and short-term morbidity were higher in our study than in period I. Our study population had a significantly higher number born with weight $<750 \mathrm{~g}(50 \%$ rise from period I) and around half of our VLBWIs were products of multiple pregnancies.

Key words: Very low birth weight infants; Very preterm infants; Outcome; Mortality; Morbidity

\section{Background}

Very low birth weight infants (VLBWI) are defined by World Health Organization as infants having a birth weight of 1500 grams or less; this is a vulnerable group of preterm babies and has high risks of mortality, multiple co-morbidities and long term poor neurodevelopmental outcomes. In developed countries, they make about $1.5 \%$ of total live births but contribute to more than $15 \%$ of neonatal intensive care unit admissions and more than $50 \%$ of the neonatal mortalities [1-3].

The survival rate of VLBWI has increased remarkably in the last three decades due to the use of antenatal steroids, pulmonary surfactant treatment, and development of perinatal health care such as respiratory and nutritional management [4-7]. These interventions have not only improved the survival of VLBWI in European and North American countries but also had a significant impact on the survival rate of VLBWI in Asian countries such as South Korea (a rapidly rising country in the last centuries), where this rate has increased up to $84.8 \%$ in 2014 after a rapid increase from $35.6 \%$ in the early 1960 s to $51.3 \%$ in the early 1990 s $[4,8]$. A few studies from different centers of Saudi Arabia $[9,10]$ showed the survival rate $83 \%$ and $92 \%$ and a morbidity pattern which is comparable to the developed countries like NRN [5].

From United Arab Emirates, Dawodu et al. reported the mortality rate of $34.5 \%$ and $12.2 \%$ for VLBWI born in Al Ain, UAE between 1995 and 1998 with birth weight 500-999g and 1000$1499 \mathrm{~g}$ respectively $[11,12]$ while a significant reduction in the mortality rate was reported among these groups by Chedid et al in 2009 from one of tertiary hospitals of same place: $31.3 \%$ and $3.6 \%$ [13]. They have also reported the major morbidities among 
these groups and compared this with previously collected data and Vermont Oxford Network (VON) percentiles [11-13].

To make further improvements in the outcomes of very low birth weight (VLBW) infants, it is crucial to evaluate differences in mortality and morbidity outcomes of neonates not only over a period of time but also between countries and continents to investigate what factors are responsible for these differences and ultimately learn from these networks. For this reason, large multicenter neonatal networks such as the National Institute of Child Health and Human Development Neonatal Research Network (NICHD), Vermont Oxford Network (VON), Neonatal Research Network of Japan (NRNJ), Canadian Neonatal Network (CNN), Australian and New Zealand Neonatal Network and International Network for Evaluation of Outcomes (iNeo) in neonates have been established. These neonatal networks analyze network data periodically to benchmark and assess quality improvement initiatives within their constituents. No neonatal network has yet been established for Gulf countries or UAE; however, a few centers from KSA and UAE are part of VON, but we usually do not get regular reports from these.

\section{Objectives}

We carried out this study to determine recent data on the mortality and morbidity rates in VLBW infants in a tertiary care center in Al Ain, UAE and compare these findings to the data published earlier from our center and from the region as well as that published by major neonatal networks such as CNN, AZNN, KNN and NRNJ.

\section{Methods}

This is a retrospective study of the outcomes of the VLBWI (with birth weights 500-1500g) admitted to a tertiary care Neonatal Unit at Tawam hospital, United Arab of Emirates during a five-year period from January $1^{\text {st }} 2011$ to December $31^{\text {st }} 2015$ till their disposal from the hospital. Patients with lethal congenital anomalies were excluded. We collected the data on the antenatal risk factors, antenatal steroids and maternal characteristics including gestation, multiple pregnancies, mode of delivery, in vitro fertilization and prolonged rupture of membranes (PROM) etc.; we also noted all the morbidities VLBWI developed during their stay in the hospital and the final outcome with regard to their survival.

Gestational age was determined by an antenatal ultrasound scan and last menstrual period calculation. PROM was defined as 18 hours prior to delivery. Intraventricular hemorrhage (IVH) was defined and graded from 1 to 4 according to Levene's classification [14]. Periventricular leukomalacia (PVL) was defined as acquired periventricular cystic lesions. Lastly, Necrotizing enterocolitis
(NEC) was defined as evidence of pneumatosis intestinalis or intestinal perforation.

Chronic lung disease (CLD) was defined as requirement for supplemental oxygen at 36 weeks postmenstrual age. Retinopathy of prematurity (ROP) stage was diagnosed by a pediatric ophthalmologist following the international classification. Patent ductus arteriosus (PDA) was diagnosed on echocardiography by a pediatric cardiologist and treatment given only to haemodynamically significant PDA as per report of echocardiography. Sepsis was confirmed by blood cultures and late onset sepsis was determined when a blood culture was positive after 72 hours of life. The length of stay was calculated as the total number days spent in the hospital while the mortality data includes all deaths occurred before disposal from the hospital.

\section{Statistical Analysis}

The data was collected and analyzed using Statistical Program for Social Survey (SPSS Version 20). Numerical data was represented by the mean (SD) or median (interquartile range) while categorical data was represented by their respective rates or proportions. The rates of IVH, PVL PDA, CLD, Sepsis and ROP were measured as a proportion of surviving infants at the age of screening and results were compared to those of the previous data from same center, regional data and other networks (KNN, CNN, and AZNN etc.). The morbidities and mortality were calculated separately for different weight groups, e.g. from 500-1000g and 1001-1500g, and compared.

\section{Results}

During the study period, a total of 497 VLBW babies were admitted to the neonatal unit (NNU), making up almost $20 \%$ of the total admissions. Twenty babies were excluded as they were outborn, 5 babies had lethal congenital malformation and 5 were $<500 \mathrm{~g}$; therefore, the final analysis was carried out on 468 VLBWIs. There was a $62 \%$ rise in the number of admission of VLBWIs as compared to those in 2008 (468/5y vs. 173/3y), the overall survival rate was around $82 \%$ (less than that of 2008), while the mean gestation and mean weight was significantly lower than the previous study ( $28.4 \pm 2.8$ vs. $29.1 \pm 2.8$ weeks and $1058 \pm 281$ vs. $1113 \pm 264$ mean \pm SD grams). In total, $82 \%$ of mothers received antenatal steroids and the PROM > 18 was present in $21 \%$ of mothers; $48 \%$ of our babies were males, about half of the VLBWI were outcome of multiple pregnancies and $18 \%$ of these were a result of in vitro fertilization. The comparison with the previous study from same center and from other networks is shown in Table 1.

Table 1: Comparison of VLBW Infant Characteristics in the study group with the reported ones in Chedid et al. study [13] and some international neonatal networks.

\begin{tabular}{|c|c|c|c|c|c|c|c|}
\hline $\begin{array}{c}\text { Patients' Characteristics Birth } \\
\text { Weight 500-1500g }\end{array}$ & $\begin{array}{c}\text { Tawam 2016 } \\
\mathbf{N = 4 6 8}\end{array}$ & $\begin{array}{c}\text { Tawam 2008 } \\
\mathbf{N = 1 7 3}\end{array}$ & $\begin{array}{c}\text { KSA 2011 } \\
\mathbf{N = 1 8 6}\end{array}$ & $\begin{array}{c}\text { UK 2017* } \\
\mathbf{N = 3 7 5 1 5}\end{array}$ & $\begin{array}{c}\text { CNN 2016 } \\
\text { N=2827 }\end{array}$ & $\begin{array}{c}\text { ANZNN } \\
\mathbf{2 0 1 6} \\
\text { N=3036 }\end{array}$ & $\begin{array}{c}\text { NRNJ 2011** } \\
\text { N=3806 }\end{array}$ \\
\hline Mean GA (wks) & 28.4 & 29.1 & 29 & NA/27.8* & NA/27.7! & NA/27.8! & 28.5 \\
\hline Mean BW (g) & 1058 & 1113 & 1062 & NA/1046* & NA/1049! & NA/1062! & 1027 \\
\hline Male $\%$ & $48.70 \%$ & $55 \%$ & $40.90 \%$ & 54.1 & NA/52\%! & $56 \% @$ & $50.40 \%$ \\
\hline
\end{tabular}




\begin{tabular}{|c|c|c|c|c|c|c|c|}
\hline Antenatal Steroid & $82 \%$ & $85.00 \%$ & $74 \%$ & $88.60 \%$ & $89 \%$ & $92 \%$ & $42.80 \%$ \\
\hline PROM $>18 \mathrm{~h}$ & $20.80 \%$ & $25.70 \%$ & NA & NA & $21.8 \% @$ & $20.7 \% @$ & $26.80 \%$ \\
\hline Cesarean section & $75.10 \%$ & $55.50 \%$ & $85 \%$ & $57 \%$ & $64 \%$ & $68.60 \%$ & $75 \%$ \\
\hline Multiple Births & $49 \%$ & $33.90 \%$ & NA & 24.3 & $27 \%$ & $29.60 \%$ & 24.9 \\
\hline
\end{tabular}

*: Data is collected from 2008-2014 [15], Mean gestation and Mean birth weights were not available for this period but taken from reports of iNeo 2008-10 [16].

!: Mean gestation and Mean birth weights were not available in the annual report of 2016; these figures are taken from reports of iNeo 2008-10 [16].

**: Figures taken from the article published in 2011 for NRNJ [19] and data collection period was from 2003-2008, but we included only 2008 for comparison .

@: For babies < 32wks, VLBW was not available separately.

Table 2 shows the comparison of survival to discharge rates for different weight groups: 500-1500g in total with sub-groups of 500-1000g and 1001-1500g for different countries and networks.
The survival of babies with birth weight of 1001-1500g in our study is about $95 \%$ which is like almost all the networks but has wider variation for extremely low birth weight infants.

Table 2: Survival to discharge: comparison of the percentage of VLBWI in total and with weight groups $500-1000 \mathrm{~g}$ and $1001-1500 \mathrm{~g}$ separately in the study group with the reported percentiles in Chedid et al. [13] and regional studies and some international neonatal networks.

\begin{tabular}{|c|c|c|c|c|c|c|c|c|c|}
\hline & $\begin{array}{c}\text { Tawam } \\
\text { (2011-15) } \\
\text { N=468 }\end{array}$ & $\begin{array}{c}\text { Tawam } \\
(2006-08) \\
2008 \mathrm{~N}=173\end{array}$ & $\begin{array}{c}\mathrm{KNN}^{*} 2017 \\
\mathbf{N}=6515\end{array}$ & $\begin{array}{c}\mathrm{KSA}^{* *} 2011 \\
\mathrm{~N}=186\end{array}$ & $\begin{array}{c}\text { CNN } 2016 \\
\text { N=2827 }\end{array}$ & $\begin{array}{c}\text { UK(2008- } \\
14) ! 2017 \\
\mathrm{~N}=37515\end{array}$ & $\begin{array}{c}\text { ANZNN } \\
2016 \\
\mathrm{~N}=3036\end{array}$ & $\begin{array}{l}\mathrm{KSA}^{* *} \\
(2016) \\
\mathrm{N}=153\end{array}$ & $\begin{array}{c}\text { NRNJ } 2011 \\
\text { N=3806 }\end{array}$ \\
\hline $500-1500 \mathrm{~g}$ & $81.80 \%$ & $85.60 \%$ & $87 \%$ & $82.80 \%$ & $92 \%$ & $87.6 \% !$ & $93.40 \%$ & $80.30 \%$ & $91.30 \%$ \\
\hline $500-1000 \mathrm{~g}$ & $63.80 \%$ & $66.70 \%$ & $73.30 \%$ & $77 \%$ & $84 \%$ & $76.80 \%$ & $87 \%$ & $58.50 \%$ & NA \\
\hline $1001-1500 \mathrm{~g}$ & $94.60 \%$ & $96.60 \%$ & $95.20 \%$ & $86.60 \%$ & $97.60 \%$ & $95.60 \%$ & $97.30 \%$ & $92 \%$ & NA \\
\hline
\end{tabular}

*: Data is collected from 2013-2015.

**: Article published in 2011, indicative data collection in 2006-08 from a tertiary care hospital in Kingdom of Saudi Arabia, 2016 from another tertiary care hospital and data collected in 2010.

! Calculated from the data present in the article (survived to discharge 31666, and missing 1385 not included in denominator).

The morbidities and complications during the stay in hospital are displayed in Table 3, showing a 64\% increase in patients with RDS who were given one or more doses of surfactant as compared to those in 2008; invasive ventilation has also increased by $32 \%$. The trend for other morbidities like CLD, NEC, PVL, and IVH is also rising except developed ROP, the frequency of which is markedly low as compared to 2008. About other networks, the rates of CLD, IVH, Sepsis and PDA are comparable but for NEC, the current study's rate is quite high while being quite low for ROP. The data for PDA and Sepsis was not available for the study carried out at Tawam in 2008.

Table 3: Short-term outcomes: comparison of the percentages of VLBWI (500-1500g) with each outcome in the study group with the reported percentiles in Chedid et al. study (13) and some international neonatal networks.

\begin{tabular}{|c|c|c|c|c|c|c|c|}
\hline Morbidities & $\begin{array}{c}\text { Tawam } 2016 \\
\text { N=468 }\end{array}$ & $\begin{array}{c}\text { Tawam } 2008 \\
\text { N=173 }\end{array}$ & $\begin{array}{c}\text { KSA } 2011 \\
\text { N=186 }\end{array}$ & $\begin{array}{c}\text { CNN } 2016 \\
\mathrm{~N}=2827\end{array}$ & $\begin{array}{c}\text { UKNC 2010* } \\
\text { N=10325 }\end{array}$ & $\begin{array}{c}\text { ANZNN } 2016 \\
\mathrm{~N}=3036\end{array}$ & $\begin{array}{c}\text { NRNJ: } 2011 \\
\text { N=3806 }\end{array}$ \\
\hline RDS/Surfactant & $69 \%$ & $41.40 \%$ & $66.70 \%$ & $55.6 !$ & NA & $56 \%$ & 52.9 \\
\hline No NPAP & $3.20 \%$ & $19.70 \%$ & NA & NA & NA & & \\
\hline NCPAP/Niv PC & $30 \%$ & $30 \%$ & 52.7 & & & $85 \%$ & \\
\hline Ventilation & $66.80 \%$ & $50 \%$ & 61.3 & & & $54 \%$ & 54.8 \\
\hline CLD & $33.50 \%$ & $12.10 \%$ & $17.70 \%$ & $30 \%$ & $32 \%$ & $31.60 \%$ & 14.6 \\
\hline ROP & $2 \%$ & $11.30 \%$ & $28.30 \%$ & $26 \%$ & & $27 \%$ & 12.5 \\
\hline $\mathrm{ROP}(\mathrm{s})$ & $0.40 \%$ & $1.60 \%$ & $3.70 \%$ & $8 \%$ & $2 \%$ & $6 \%$ & \\
\hline NEC & $10 \%$ & $5.80 \%$ & $7.50 \%$ & $5 \%$ & NA & 3.6\%@ & 3.3 \\
\hline IVH all grades & $22 \%$ & $17.50 \%$ & $12.90 \%$ & $21.50 \%$ & & $20.40 \%$ & 12.9 \\
\hline IVH $3 \& 4$ & $9.90 \%$ & $9.60 \%$ & $8.10 \%$ & $12 \%$ & $6 \%$ & $4.50 \%$ & $4.10 \%$ \\
\hline PVL & $3.80 \%$ & $2.80 \%$ & $3.80 \%$ & $2.60 \%$ & $2 \%$ & 1.5\%@ & 3.7 \\
\hline EOSepsis LOSepsis/sepsis & $\begin{array}{l}0.85 \\
18 \% \\
\end{array}$ & NA & $\begin{array}{c}1.6 \% \\
21.9 \%\end{array}$ & $\begin{array}{l}1.1 \% \\
13 \%\end{array}$ & & $\begin{array}{l}1.5 \% \\
10 \%\end{array}$ & $8.90 \%$ \\
\hline PDA (treated)a & $18.50 \%$ & NA & $19.90 \%$ & $18.80 \%$ & & NA & 15.3 \\
\hline
\end{tabular}

a: In our study, total PDA cases were $32 \%,(148)$ and in CNN it is $36.7 \%$ (1037), treated out of cases were $51.4 \%$ for CNN and $57.4 \%$ in our data, total PDA $37 \%$ (1415) and treated out of that $41 . \%$ (580) in NRJN, in KSA $31.2 \%$ (58) DX as PDA and treated 37.

*: Figures taken from an article where comparison on various neonatal network was done [15], no exclusive report is available.

!: Figures for $<31 \mathrm{wks}$, for $<1.5 \mathrm{~kg}$ not mentioned [1].

@: Figures for $<32 w k s$, not available separately for VLBW. 
Table 4 shows mortality and short-term outcomes in subgroups 500-1000g, 1001-1500g of VLBWIs in our study, Chedid et al.'s study and other international neonatal networks. The comparison

Table 4: Morbidities in Babies.

\begin{tabular}{|c|c|c|c|c|c|c|c|c|}
\hline & \multicolumn{4}{|c|}{ Weight 500-1000g } & \multicolumn{4}{|c|}{ Weight 1000-1500g } \\
\hline & $\begin{array}{c}\text { Tawam } 2016 \\
\text { N=196 }\end{array}$ & $\begin{array}{c}\text { Tawam } 2008 \\
\quad \mathrm{~N}=63\end{array}$ & $\begin{array}{c}\text { CNN } 2016 \\
\mathrm{~N}=1182\end{array}$ & $\begin{array}{l}\text { AZNN } 2016 \\
\text { N=1164 }\end{array}$ & $\begin{array}{c}\text { Tawam } 2016 \\
\text { N=272 }\end{array}$ & $\begin{array}{c}\text { Tawam } 2008 \\
\text { N=110 }\end{array}$ & $\begin{array}{c}\text { CNN } 2016 \\
N=1645\end{array}$ & $\begin{array}{c}\text { AZNN } 2016 \\
\mathbf{N}=1872\end{array}$ \\
\hline $\begin{array}{c}\text { RDS/ } \\
\text { Surfactant }\end{array}$ & $92.20 \%$ & NA & NA & $80 \%$ & $54.80 \%$ & NA & NA & 40 \\
\hline No NPAP & 0 & 0 & NA & & $5.50 \%$ & $30.90 \%$ & NA & \\
\hline NCPAP /NIV & $7.60 \%$ & $22.20 \%$ & & 88.4 & $44.50 \%$ & $34.50 \%$ & & 82.5 \\
\hline Ventilation & $92.40 \%$ & $77.80 \%$ & & 79.3 & $50 \%$ & $38.50 \%$ & & 37.7 \\
\hline CLD & $46.40 \%$ & $23.80 \%$ & $52 \%$ & $56 \%$ & $16 \%$ & $5.50 \%$ & $12.90 \%$ & $16.30 \%$ \\
\hline ROP & $4 \%$ & $29.30 \%$ & 55.5 & 55.5 & $1 \%$ & $2.40 \%$ & 19.5 & 15 \\
\hline $\mathrm{ROP}(\mathrm{s})$ & $1 \%$ & $4.80 \%$ & 14.1 & $17 \%$ & $0.40 \%$ & 0 & 0.94 & 1.1 \\
\hline NEC & $15.30 \%$ & $7.90 \%$ & $7.20 \%$ & 7.5@ & $6.30 \%$ & $4.50 \%$ & $3.80 \%$ & 1.5@@ \\
\hline IVH all grades & $37 \%$ & $25 \%$ & $26 \% * *$ & 30.4 & $12.90 \%$ & $11.80 \%$ & $10.9 \% * * * *$ & 13.6 \\
\hline IVH $3 \& 4$ & $19.40 \%$ & $11.60 \%$ & $11.60 \%$ & 8.6 & $2.90 \%$ & $0.80 \%$ & $4.40 \%$ & 2.3 \\
\hline PVL & $3 \%$ & $6.10 \%$ & $4.90 \%$ & NA & $2.60 \%$ & 1.1 & 1.4 & NA \\
\hline EOSepsis & & NA & & 2.2 & & & & \\
\hline LOSepsis & 27.5 & & 23.5 & 20.2 & $12 \%$ & NA & 3.4 & 3.9 \\
\hline PDA (treated) & $33.50 \%$ & NA & $33.8 \% *$ & NA & $7.70 \%$ & NA & $14 \%^{* * *}$ & \\
\hline
\end{tabular}

*: Total cases were $54 \%$ (646) out of which about $62 \%$ treated either medically or surgically (400).

**: GM hemorrhage not included (35\%).

***: From total cases, Dx cases of PDA were $23.7 \%$ (391) and out which $40.6 \%$ (159) got treated.

****: GM Hge (20.8\%).

@: figures for $<28$ wks of gestation, not separate for VLBW.

Table 5: Comparison of length of stay at Tawam in 2016 and 2008.

\begin{tabular}{|c|c|c|}
\hline & Tawam 2016 & Tawam 2008 \\
\hline & $\begin{array}{c}\text { Mean (SD)/ } \\
\text { Median(IQR) }\end{array}$ & $\begin{array}{c}\text { Mean (SD)/ } \\
\text { Median(IQR) }\end{array}$ \\
\hline \multicolumn{3}{|c|}{ ALOS all Included } \\
\hline $500-1000 \mathrm{~g} \mathrm{BW}$ & $\begin{array}{c}75.7(69.7) / 72.5(16- \\
91)\end{array}$ & $63.9(43.8)$ \\
\hline $1001-1500 \mathrm{~g} \mathrm{BW}$ & $\begin{array}{c}47.8(37.6) / 42.5(30- \\
56)\end{array}$ & $43.1(23.7)$ \\
\hline $500-1500 \mathrm{~g}$ BW & $60(54.8) / 49(30-76)$ & $50.9(34.1)$ \\
\hline \multicolumn{3}{|c|}{ ALOS Expired: } \\
\hline $500-1000 \mathrm{~g}$ & $28.9(55.5) / 7(1-31)$ & $20.4(23.9)$ \\
\hline $1001-1500 \mathrm{~g}$ & $38.2(68.7) / 15.5(1-26)$ & $26.5(13)$ \\
\hline $500-1500 \mathrm{~g}$ & $30.4(57.5) / 9(1-29)$ & $21.4(22.4)$ \\
\hline & ALOS Survived \\
\hline $500-1000 \mathrm{~g}$ & $103(62) / 85(69-116)$ & $85.7(34.2)$ \\
\hline $1001-1500 \mathrm{~g}$ & $50(34.8) / 44(32-57)$ & $43.8(23.8)$ \\
\hline $500-1500 \mathrm{~g}$ & $67(52) / 55(37-80)$ & $56.1(33.2)$ \\
\hline
\end{tabular}

\section{Discussion}

In the present study, the survival rate of VLBWIs till discharge and rate of most of the short-term morbidities are comparable to the regional and previous studies from the same center with a small decrease in survival rate, especially in the weight group between $500-1000 \mathrm{~g}[9,10,13]$. However, when we pay attention to the basic characteristics of the population in the two groups, we can observe of length of stay of all groups can be seen in Table 5, showing the mean length of stay for all groups to be significantly higher in 2016 as compared to that of 2008 . 
the previous study from same center [13]; however, it is more than $75 \%$ in the UK [15] and more than $80 \%$ in most other networks such as Canadian [1] and Australian and New Zealand networks [2]. The main difference in the morbidities of this population is the incidence of NEC and late onset Sepsis, which itself carries a high rate of mortality among this group of population. The only cause which could be plausible for this is that the rate of multiple pregnancies in the present study was high (49\% as compared to the $27-33 \%$ in other studies). Multiple births carry a higher risk for NEC than single births. Similarly, if we compare the rate of late onset sepsis, it is found highest among our study population: $27.5 \%$ in VLWBI (18\% in all) as compared to $20-23 \%$ (8-13\% in all). Furthermore, differences in the outcomes of VLBW infants between countries and networks could be due to a multitude of factors, including differences in population characteristics, severity of illness, processes of care, or delivery of health care [16].

In addition to the above, NICHD Neonatal Research Network $[5,6]$ data suggests that a plateau in VLBW infant survival rates might have been reached despite increased use of prenatal corticosteroid treatment, prenatal antibiotic treatment, and early neonatal surfactant treatment. This data may partially explain why our outcome of VLBWI did not improve compared to the previous data published by Chedid et al. [13].

Previous reports have compared mortality and morbidity of VLBW and ELBW infants in various countries, regions, or networks and identified that there are wide variations in mortality and morbidity rates of these infants [1,15-19]. Although these reports have observed a steady improvement in neonatal mortality and morbidity in the last few decades, recent results published by several international neonatal networks have been variable. Some networks have indicated a halt or worsening in the progress while others have reported improved outcomes $[5,6,15,17]$.

These factors could explain the differences in outcomes between our results and the previous reported study from our center as well as between other international neonatal networks.

\section{Recommendations}

- To conduct more detailed analyses of practice differences in developed countries and neonatal networks to specifically target quality improvement initiatives. It is also important to compare follow-up data to assess longterm neurodevelopmental outcomes and the quality of life of survivors.

- To establish a neonatal network in UAE like health care systems in the surrounding Gulf countries, which will be of great benefit. Once national neonatal networks have been established, inter-regional neonatal network comparisons will be possible by using similar methods or collaboratively developing a minimal data set to identifying areas of improvement.

\section{Conclusion}

This is the second study conducted in our tertiary NNU which addresses the mortality and morbidity of VLBWI in UAE. A slight increase in mortality and short-term morbidity rates in the study population was noted along with marked increment in number of extreme premature infants as well as product of multiple gestations.

\section{Acknowledgement}

None.

\section{Conflict of Interest}

No conflict of interest.

\section{References}

1. (2016) Canadian Neonatal Network. Annual Report.

2. (2016) Australian \& New Zealand Neonatal Network. Report of the Australian and New Zealand Neonatal Network.

3. Watson SI, Arulampalam W, Petrou S, Marlow N, Morgan AS, et al. (2014) The effects of designation and volume of neonatal care on mortality and morbidity outcomes of very preterm infants in England: retrospective population-based cohort study. BMJ Open 4(7): 1-9.

4. Shim JW, Jin HS, Bae CW (2015) Changes in Survival Rate for Very-LowBirth-Weight Infants in Korea: Comparison with Other Countries. J Korean Med Sci 30(Suppl 1): p. S25-S34.

5. Stoll BJ, Hansesn NI, Bell EF, Shankaran S, Laptook AR, et al. (2010) Neonatal Outcomes of Extremely Preterm Infants from the NICHD Neonatal Research Network. Pediatrics 126(3): 443-456.

6. Stoll BJ, Hansesn NI, Bell EF, Walsh MC, Carlo WA, et al. (2015) Trends in Care Practices, Morbidity, and Mortality of Extremely Preterm Neonates, 1993-2012. JAMA 314(10): 1039-1051.

7. Rysavy MA, Li L, Bell EF, Das A, Hintz SR, et al. (2015) Between-Hospital Variation in Treatment and Outcomes in Extremely Preterm Infants. The New England journal of medicine 372(19): 1801-1811.

8. Chung SH, Bae CW (2017) Improvement in the Survival Rates of Very Low Birth Weight Infants after the Establishment of the Korean Neonatal Network: Comparison between the 2000s and 2010s. J Korean Med Sci 32(8): 1228-1234.

9. Al Qurashi FO, Yousef AA, Awary BH (2016) Epidemiological aspects of prematurity in the Eastern region of Saudi Arabia. Saudi Med J 37(4): 414-419.

10. Al Hazzani F, Al Alaiyan S, Hassanein J, Khadawardi E (2011) Short-term outcome of very low-birth-weight infants in a tertiary care hospital in Saudi Arabia. Ann Saudi Med 31(6): 581-585.

11. Dawodu A, Varady E, Verghese M, Al Gazali LI (2000) Neonatal audit in the United Arab Emirates: a country with a rapidly developing economy. East Mediterr Health J 6(1): 55-64.

12. Dawodu A, Varady E, Nath KNR, Rajan TV (2005) Neonatal outcome in the United Arab Emirates: the effect of changes in resources and practices. Eastern Mediterranean Health Journal 11(4): 673-679.

13. Chedid F, Shanteer S, Haddad H, Musharraf I, Shihab Z, et al. (2009) Short-term outcome of very low birth weight infants in a developing country: comparison with the Vermont Oxford Network. J Trop Pediatr 55(1): 15-19.

14. Levene MI, Fawer CL, Lamont RF (1982) Risk factors in the development of intraventricular haemorrhage in the preterm neonate. Archives of disease in childhood 57(6): 410-417.

15. Santhakumaran S, Statnikov Y, Gray D, Battersby C, Ashby D, et al. (2018) Survival of very preterm infants admitted to neonatal care in England 2008-2014: time trends and regional variation. Archives of disease in childhood. Fetal and neonatal edition. 103(3): F208-F215.

16. Shah PS, Lui K, Sjors G, Mirea L, Reichman B, et al. (2016) Neonatal Outcomes of Very Low Birth Weight and Very Preterm Neonates: An International Comparison. J Pediatr 177: 144-152.

17. Isayama T, Lee SK, Mori R, Kusuda S, Fujimura M, et al. (2012) Comparison of mortality and morbidity of very low birth weight infants between Canada and Japan. Pediatrics 130(4): e957-e965. 
18. Chow S, Chow R, Popovic M, Lam M, Popovic M, et al. (2015) A selected review of the mortality rates of neonatal intensive care units. Frontiers in public health $3: 225$.
19. Kusuda S, Fujimura M, Uchiyama A, Totsu S, Matsunami K (2012) Trends in morbidity and mortality among very-low-birth-weight infants from 2003 to 2008 in Japan. Pediatr Res 72(5): 531-538. 